\title{
BMJ Open LIFEStyle, Prevention and Risk of Acute PaNcreatitis (LIFESPAN): protocol of a multicentre and multinational observational case-control study
}

\author{
Balázs Koncz, ${ }^{1}$ Erika Darvasi, ${ }^{1}$ Dalma Erdősi, ${ }^{2}$ Andrea Szentesi, ${ }^{1,2}$ Katalin Márta, ${ }^{2}$ \\ Bálint Erőss, ${ }^{2}$ Dániel Pécsi, ${ }^{2}$ Zoltán Gyöngyi, ${ }^{3}$ János Girán, ${ }^{3}$ Nelli Farkas, ${ }^{2,4}$ \\ Maria Papp, ${ }^{5}$ Eszter Fehér, ${ }^{5}$ Zsuzsanna Vitális, ${ }^{5}$ Tamás Janka, ${ }^{5}$ Áron Vincze, ${ }^{6}$ \\ Ferenc Izbéki, ${ }^{7}$ Veronika Dunás-Varga, ${ }^{7}$ László Gajdán, ${ }^{7}$ Imola Török, ${ }^{8}$ \\ Sándor Károly, ${ }^{9}$ Judit Antal, ${ }^{2}$ Noémi Zádori, ${ }^{2}$ Markus M Lerch, ${ }^{10}$ \\ John Neoptolemos, ${ }^{11}$ Miklós Sahin-Tóth, ${ }^{12}$ Ole H Petersen, ${ }^{13}$ Péter Hegyi

To cite: Koncz B, Darvasi E, Erdősi D, et al. LIFEStyle, Prevention and Risk of Acute PaNcreatitis (LIFESPAN): protocol of a multicentre and multinational observational case-control study. BMJ Open 2020;10:e029660. doi:10.1136/ bmjopen-2019-029660

- Prepublication history and additional material for this paper are available online. To view these files, please visit the journal online (http://dx.doi. org/10.1136/bmjopen-2019029660).

BK and ED are joint first authors.

Received 04 February 2019 Revised 28 November 2019 Accepted 02 December 2019

Check for updates

(C) Author(s) (or their employer(s)) 2020. Re-use permitted under CC BY-NC. No commercial re-use. See rights and permissions. Published by BMJ.

For numbered affiliations see end of article.

Correspondence to

Dr Péter Hegyi;

p.hegyi@tm-centre.org

\section{ABSTRACT}

Introduction Acute pancreatitis (AP) is a life-threatening inflammatory disease of the exocrine pancreas which needs acute hospitalisation. Despite its importance, we have significant lack of knowledge whether the lifestyle factors elevate or decrease the risk of AP or influence the disease outcome. So far, no synthetising study has been carried out examining associations between socioeconomic factors, dietary habits, physical activity, chronic stress, sleep quality and AP. Accordingly, LIFESPAN identifies risk factors of acute pancreatitis and helps to prepare preventive recommendations for lifestyle elements.

Methods and analysis LIFESPAN is an observational, multicentre international case-control study. Participating subjects will create case and control groups. The study protocol was designed according to the SPIRIT guideline. Patients in the case group $(n=1700)$ have suffered from AP (alcohol-induced, $n=500$; biliary, $n=500$; hypertriglyceridemiainduced, $n=200$; other, $n=500$ ); the control group subjects have no AP in their medical history. Our study will have three major control groups $(n=2200)$ : hospital-based $(n=500)$, population-based $(n=500)$ and aetiology-based (alcohol, $n=500$; biliary, $n=500$ and hypertriglyceridemia, $n=200$ ). All of them will be matched to the case group individually by gender, age and location of residence. Aggregately, 3900 subjects will be enrolled into the study. The study participants will complete a complex questionnaire with the help of a clinical research administrator/study nurse. Analysis methods include analysis of the continuous and categorical values.

Ethics and dissemination The study has obtained the relevant ethical approval (54175-2/2018/EKU) and also internationally registered (ISRCTN25940508). After obtaining the final conclusions, we will publish the data to the medical community and will also disseminate our results via open access.

Trial registration number ISRCTN25940508; Pre-results.

\section{INTRODUCTION}

Acute pancreatitis (AP) is a life-threatening inflammatory disease of the exocrine

\section{Strengths and limitations}

- Innovative results are to be expected concerning that contribution of lifestyle factors to acute pancreatitis is poorly researched and known; therefore, evidence-based preventive suggestions might be carried out.

- LIFESPAN study will include a huge extension of examined patient population because of the three major control groups; all of them will be matched to the case group individually, and this will elevate the strength of our study.

- The study contains questionnaires only with no additional costs; therefore, the study has an excellent cost:benefit ratio.

- The database will mostly consist of patient-delivered data.

- The questionnaire requires extensive time which needs plenty of attention from the administrators and subjects as well.

pancreas which needs acute hospitalisation. Despite its importance, we have significant lack of knowledge concerning whether lifestyle factors elevate or decrease the risk of AP or influence the disease outcome. This insufficient information is even more problematic since (1) there is no specific treatment for the disease, therefore prevention would be very important; and (2) $20 \%$ of all AP is recurrent so lifestyle suggestions decreasing the risk of an additional attack could be highly efficient.

Genetic and environmental factors play a significant role in disease development and outcome. Of course, in most of the cases, the genetic background cannot be changed, but the environmental factors. Dietary habits, socioeconomic status, physical activity, stress 
or sleeping habits have been proven to play a crucial role in many diseases.

\section{Dietary factors}

Association of diet and the risk of diseases is well known in a lot of diseases, for example, in type 2 diabetes mellitus ${ }^{12}$ and coronary heart disease, ${ }^{3}$ and there is an ongoing multicentre prospective study about diet and cancer by the European Prospective Investigation into Cancer and Nutrition (EPIC). ${ }^{4}$

Recently, a multiethnic cohort study was published about dietary factors that are associated with risk of pancreatitis. ${ }^{5}$ Data source was a retrospective multiethnic cohort in Hawaii and Los Angeles (215, 251 adult men and women were enrolled at the age of 45-75 years at baseline, from 1993 to 1996). They used hospitalisation claim files (1993-2012) to identify pancreatitis and a self-administered quantitative food frequency questionnaire. ${ }^{6}$ The main findings of this study are that intakes of saturated fat and cholesterol, and their food sources (red meat, eggs) positively associate with gallstone-related AP, intakes of fibre inversely associate with AP, intakes of vitamin D (mainly milk) inversely associate with gallstonerelated AP and coffee consumption protects against AP (not related to gallstones).

The association of vegetable, fruit and fish consumption with non-gallstone AP was examined in a Swedish prospective cohort study. ${ }^{78}$ Their conclusion is that vegetable consumption, but not fruit consumption, may play a role in the prevention of non-gallstone-related AP, and the consumption of total fish may be associated with decreased risk of non-gallstone-related AP.

\section{Physical activity}

Several studies were published about physical activity and public health. ${ }^{9}{ }^{10}$ Regular exercise offers protection against cardiovascular diseases and type 2 diabetes mellitus. ${ }^{11}$ So far, not many studies have investigated the association between general physical activity and AP, although there are some surprising case reports about marathon pancreatitis (extreme long-distance running results in AP). ${ }^{12}$ Results of a prospective cohort study show that there is an inverse association between physical activity and risk of $\mathrm{AP} .^{13}$

\section{Socioeconomic status}

Socioeconomic status (SES) is strongly associated with risk of disease and mortality. ${ }^{14}$ SES includes the economic (measured by income), social (measured by education) and work status (measured by occupation). A clear relationship was also found between socioeconomic deprivation and incidence of AP in a prospective observational study of AP in the North of England which was largely explained by a higher incidence of alcoholic aetiology. ${ }^{15}$

\section{Stress}

Chronic stress may also cause disease, either because of molecular changes ${ }^{16}$ or because of increasing the probability of smoking, alcohol or drug consumption. Research shows that stress can contribute to the development of major illnesses, such as heart diseases, depression and obesity (www.apa.org); however, no information is available concerning the effect of stress on the incidence of AP.

\section{Sleep quality}

Currently, there are no studies about the association of sleep quality and AP; however, several articles claim that sleep deprivation or obstructive sleep apnoea is associated with elevated levels of $\mathrm{C}$ reactive protein, ${ }^{17}{ }^{18}$ which is the stable marker of inflammation and usually high in AP. ${ }^{19}$

In this study, our aim is to examine these healthaffecting individual lifestyle factors that seem to influence the development and outcome.

\section{METHODS}

The study has been initiated by the Hungarian Pancreatic Study Group and endorsed by the International Association of Pancreatology and was structured following the SPIRIT 2013. ${ }^{20}$

\section{Design}

LIFESPAN is an observational, multicentre and multinational case-control study. The data collection is based on questionnaires and medical histories. Relevant data will be prospectively collected from patients and controls. The questionnaires A-F and $\mathrm{P}$ (seven questionnaires in the case group, six for the control group) about the different fields of the patients' lifestyle will be filled with the help of trained administrators by a one-time meeting. Patients enrolled into the case group have suffered from AP; the control group subjects must not have AP in their medical history.

\section{Study organisation, committees and boards}

The co-ordinator and designer of the LIFESPAN study is the Hungarian Pancreatic Study Group (HPSG-co-ordinating society, https://tm-centre.org/en/study-groups/ hungarian-pancreatic-study-group/). HPSG has been running high-quality international, multicentre clinical trials since $2014^{21-25}$ and has published the relevant guidelines for pancreatic diseases to improve patient care in pancreatology. ${ }^{26-29}$

The study will be supported by four committees:

\section{Steering committee (SC)}

The committee will be led by $\mathrm{PH}$ (corresponding investigator, gastroenterologist and internal medicine specialist). The members will be in Szeged (HU): ED (principal investigator); Debrecen (HU): MP (gastroenterologist), ZV (gastroenterologist), TJ (gastroenterologist); Pécs (HU): AS (multidisciplinary unit specialist), DE (co-principal investigator), KM (trial management specialist), BE (gastroenterologist), ZG (public health specialist), JG (public health specialist), AV (gastroenterologist); Székesfehérvár (HU): FI (gastroenterologist), LG (gastroenterologist); Targu Mures (RO): IT 
(gastroenterologist). KM is a trial management specialist, whereas AS leads the multidisciplinary core facility which will assist the scientists to run the study successfully.

\section{International translational advisory board (ITAB)}

The board will consist of a gastroenterologist (MML), a surgeon and two basic scientists (JN, MS-T, OHP). The ITAB will continuously monitor the progress of the study and will advise the SC.

\section{Data monitoring committee (DMC)}

DMC will handle all the data and ensure that the data in the electronic case report form (eCRF) are accurate, complete and legible. Data Management Plan will describe the detailed data flow. The Data Manager will validate the data from completed eCRFs, according to a Data Cleaning Plan. Any missing, implausible or inconsistent recordings in the eCRFs will be referred back to the Investigator using a data query form and be documented for each individual subject before clean file status is declared. All changes to eCRFs will be recorded. In case of important protocol modifications, DMC will report it to the SC.

\section{Premature termination of the study}

Interim analysis will be carried out after half of the presumed number of patients have completed the study. Sample sizes for all questionnaires will be reassessed and modified accordingly. In addition, DMC independently will assess the study-related documents and activities, with the aim of ensuring the respect of subjects' right and to guarantee the plausibility of clinical data.

\section{Sponsor}

The sponsor of the study is the Centre for Translational Medicine at the University of Pécs Medical School (co-ordinating institution and sponsor, www.tm-centre.org).

\section{Study population}

All patients diagnosed with AP in participating institutions will be informed concerning the possibility of taking part of the LIFESPAN study.

Case group (1700 cases): Patients in the case group will be divided into four groups depending on the causative agents of the AP (alcohol-induced, biliary, hypertriglycieridemia and other). Taking into consideration the central limit theorem, ${ }^{30} 500$ patients will be enrolled in all groups, but the hypertriglyceridemia-induced group, where due to the low prevalence level, only 200 subjects will be collected. With the sample size of 500 , it is thought to be possible to safely analyse the relationship between two variables that contain up to four variable values each. Altogether, we plan to enroll 1700 individuals as cases. This way, the required number of respondents can be provided for a comparative analysis between the members of the case and control groups as well as for an exploratory study within a given case group.

\section{Control group (2200 cases)}

Our study will have three major control groups; all of them will be matched to the case group individually in order to avoid admission rate bias.

(1) Hospital-based control group: we will enrol patients in other clinical departments (eg, Traumatology Department, Ophthalmic Department, 500 patients); (2) Population-based control group: we will enrol people according to a plan based on gender:age:location of residence ratios in the case group (500 patients); (3) Aetiology-based control group: we will enrol people matched to the three aetiology factors of the four case groups (500, 500 and 200, respectively).

\section{Inclusion criteria}

The criteria for inclusion in the study in case groups (A) in general: (1) patients above 18 years; (2) diagnosed AP on the basis of the ' 2 out of 3' rules of International Association of Pancreatology/American Pancreatic Association (IAP/APA) guideline:

(a) upper abdominal pain; (b) serum amylase or lipase $>3$ times the upper limit of normal range; (c) characteristic findings on pancreatic imaging; (3) written informed consent form is signed. According to the aetiology: (A1) in alcohol aetiology group: patients consuming $>5$ drinks per day or $>35$ drinks per week for both sexes $(=8.75$ units per day; 61.25 units per week) shall be included. Please note that 1 unit of alcohol $=10 \mathrm{~mL}$ or $8 \mathrm{~g}$ of pure $(100 \%)$ alcohol $^{31}$; (A2) in gallstone aetiology group: presence of gallstone (not sludge); (A3) in hypertriglyceridemia aetiology group: triglyceride level in blood over $11 \mathrm{mmol} / \mathrm{L}^{32}$; (A4) in 'other' aetiology group: the causative agents do not match either of the first three groups, AP is induced by, for example, endoscopic retrograde cholangiopancreatography (ERCP) (post-ERCP pancreatitis), virus infection, trauma, medicine (drug-induced pancreatitis), congenital anatomical malformation, cystic fibrosis, genetics, gluten-sensitive enteropathy and so on.

The criteria for inclusion in the study for control groups (B, C and D) in general: (1) patients above 18 years; (2) absence of AP at present as well as in the medical history; (3) signed written informed consent form.

\section{According to the aetiology of the case groups (B1)}

In alcohol group: patients consuming $>5$ drinks per day or $>35$ drinks per week for both sexes $(=8.75$ units per day; 61.25 units per week) shall be included. Please note that 1 unit of alcohol $=10 \mathrm{~mL}$ or $8 \mathrm{~g}$ of pure $(100 \%)$ alcohol $^{31}$; (B2) in gallstone group: presence of gallstone (not sludge); (B3) in hypertriglyceridemia group: triglyceride level over $11 \mathrm{mmol} / \mathrm{L}^{32}$ The criteria for inclusion in the study for hospital-based control group (C): patients are hospitalised for other than internal medicine-associated disease, such as hospital admissions in Traumatology or Ophthalmic Department. The criterion for inclusion in the study for population-based control group (D): not hospitalised general population. 


\section{Exclusion criteria}

The criteria for exclusion in all groups: (1) patients do not have reliable information or data; (2) patients may not adhere; (3) unclear aetiology.

\section{Withdrawal of a subject from the study}

According to the ethical regulations, individuals are allowed to leave the study at any time without any negative consequences. Patients in the case group will be recruited during their hospital stay. Individuals for the control group are either spread among different units or not hospitalised at all. In the study, the participants in the case and in the control groups will be matched individually and continuously by gender, age and residence. Age and sex will be matched precisely in each case; location of residence will be considered by the range of population. The length of the data collection is 6 years and the data analysis takes another half a year.

Data collection and follow-up: Each participant (3900), if he/she meets the inclusion criteria and signs the informed consent form, will be questioned by a clinical research administrator/study nurse who is fully trained before how to fill properly the questionnaires A-F and P. Since trained clinical research administrators will collect information, missing data will be unlikely. The schedule of enrolment and assessments will be carried out according to the SPIRIT Guideline (online supplementary figure 1).

In Form $A$ (A1 and A2), we will collect general information about personal details and current status. The subjective social status will be evaluated with the SES ladder (MacArthur Scale of Subjective Social Status, http://www.macses.ucsf.edu). It is a widespread instrument in large epidemiological European and US studies and found to be significantly associated with health status, independently of objective socioeconomic indicators ${ }^{33}$ (table 1).

In Form B (B1 and B2), we will collect information about patients' medical history based on Acute Pancreatitis Questionnaire of the registry for pancreatic patients operated on by the Hungarian Pancreatic Study Group. ${ }^{34}$ This online registry was established for recording data of patients with pancreatic diseases in 2012 (www.tm-centre. org), including details on smoking, alcohol consumption, other risk factors, medical history and the course and outcome of the disease (table 1 ).

In Form C (C1 and C2), we will collect data about participants' dietary habits. Food Frequency Questionnaires (FFQs) are commonly used in epidemiological studies to assess the dietary intake of large populations. Their popularity derives from ease of administration, ability to assess dietary intake over a defined period of time and low costs. ${ }^{35}$ The Diet History Questionnaire II (DHQII) and Diet*Calc Analysis Software is a valid tool to measure dietary habits ${ }^{36-38}$ and free to use. It is a very detailed quantitative FFQ with the most general foods and drinks (table 1).

In Form D (D1 and D2), we will measure the participants' physical activity (PA) level with a frequently used epidemiology questionnaire, namely, the International Physical Activity Questionnaire. ${ }^{39}$ We will use the long, usual week version (27-item) in the general part of our PA questionnaire. It contains details about the participants' vigorous PA, moderate PA, walking and sitting habits (table 1 ).

In Form E (E1 and E2), we will evaluate the participants' chronic stress level with the Perceived Stress Scale. ${ }^{40}$ It is the most widely used psychological instrument for the measuring of chronic stress effect. ${ }^{41-43}$ We chose the

Table 1 Title and source of the seven questionnaires to be used for data collection in LIFESPAN study

\begin{tabular}{|c|c|c|}
\hline Form & Title & Source \\
\hline $\begin{array}{l}\text { Form B } \\
\text { (B1 and B2) }\end{array}$ & $\begin{array}{l}\text { DETAILS FROM THE MEDICAL } \\
\text { HISTORY }\end{array}$ & $\begin{array}{l}\text { Acute Pancreatitis Questionnaire (Registry for Pancreatic Patients by } \\
\text { Hungarian Pancreatic Study Group) }\end{array}$ \\
\hline $\begin{array}{l}\text { Form C } \\
\text { (C1 and C2) }\end{array}$ & DIETARY HABITS & $\begin{array}{l}\text { Diet History Questionnaire, Version 2.0. National Institutes of Health, } \\
\text { Epidemiology and Genomics Research Program, National Cancer Institute, } \\
2010\end{array}$ \\
\hline $\begin{array}{l}\text { Form D } \\
\text { (D1 and D2) }\end{array}$ & PHYSICAL ACTIVITY & International Physical Activity Questionnaire (long, usual week version) \\
\hline $\begin{array}{l}\text { Form E } \\
\text { (E1 and E2) }\end{array}$ & STRESS & Percieved Stress Scale (10-item version) \\
\hline $\begin{array}{l}\text { Form F } \\
\text { (F1 and F2) }\end{array}$ & SLEEP QUALITY & Pittsburgh Sleep Quality Index \\
\hline
\end{tabular}

ERCP, endoscopic retrograde cholangiopancreatography; IAP/APA, International Association of Pancreatology/American Pancreatic Association. 
10-item version which has high validity and reliability. The time range in the general part is different from the original questionnaire (last year vs last month) (table 1).

In Form F (F1 and F2), we will collect data about participants' sleeping habits. We will apply the widely used Pittsburgh Sleep Quality Index (PSQI), which evaluates the participants' sleeping quality. ${ }^{44}$ We skip the 10th question about bed partner or roommate because the bed partner will not be at the interview probably and this question does not count in the evaluation. The time range in the general part is also different from the original questionnaire (last year vs last month) (table 1).

In Form P, we will collect data about patients' acute pancreatitis using the appropriate questions of Acute Pancreatitis Questionnaire (see Form B) (table 1).

Electronic case report forms will be developed and will be available online (www.tm-centre.org).

\section{Patient and public involvement}

Ten individuals were involved in the testing procedure of the study in order to optimise the feasibility.

\section{Endpoints}

Endpoints will be provided by each question of the questionnaires.

\section{Form A}

Age, race, location, body weight, body height, body mass index (BMI), waist circumference, education, occupation, income, subjective social status.

\section{Form B}

Alcohol consumption (frequency, amount), smoking (frequency, amount), drug abuse (frequency, amount), diabetes mellitus (type), lipid metabolism disorder (type), any disease of the pancreas, pancreas, disorders in family history, congenital anatomical malformation of the pancreas, other illnesses, medications, diet.

\section{Form C}

A total of 176 nutrients, dietary constituents and food groups, carbohydrate constituents, macronutrients and energy, fats, fatty acids, cholesterol, protein constituents, vitamins, minerals, carotenoids and tocopherols, dietary constituents from supplements, other, food pyramid equivalents, Healthy Eating Index (HEI-2010) ((0-100); Good: >80, Needs improvement: 51-80; Poor: <51) (https:// www.cnpp.usda.gov/sites/default/files/healthy_eating index/HEI89-90report.pdf) (table 2).

\section{Form D}

Continuous Scores (metabolic equivalent of task (MET)minutes/week), Total physical activity (consists of Total walking activity (MET-minutes/week), Total moderate activity (MET-minutes/week), Total vigorous activity (MET-minutes/week), Average sitting (min/day)), Categorical score (level of PA: Low-This is the lowest level of physical activity. Those individuals who do not meet criteria for Categories 2 or 3 are considered to have a 'low' physical activity level. Moderate: 3 or more days of vigorous-intensity activity of at least 20 min per day OR 5 or more days of moderate-intensity activity and/or walking of at least 30 min per day OR 5 or more days of any combination of walking, moderate-intensity or vigorous intensity activities achieving a minimum Total physical activity of at least 600 MET-minutes/week. High: vigorousintensity activity on at least 3 days achieving a minimum Total physical activity of at least 1500 MET-minutes/week OR 7 or more days of any combination of walking, moderate-intensity or vigorous-intensity activities achieving a minimum Total physical activity of at least 3000 MET-minutes/week) (https://sites. google.com/site/theipaq/scoring-protocol) (table 2).

\section{Form $\mathrm{E}$}

Total Perceived Stress Scale (PSS) Score (0-40) (Categories: Low perceived stress—scores ranging from 0 to 13; Moderate perceived stress-scores ranging from 14 to 26; High perceived stress—scores ranging from 27 to 40) (https://das.nh.gov/ wellness/Docs/Percieved_Stress_Scale.pdf) (table 2).

\section{Form $\mathrm{F}$}

Global PSQI Score (0-21) (which consists of Subjective sleep quality (0-3): Sleep latency (0-3), Sleep duration (0-3), Habitual sleep efficiency (0-3), Sleep disturbances (0-3), Use of sleeping medication (0-3), Daytime dysfunction (0-3)), Categories (empirically derived cut-off score): Score <5: Good sleepers; Score >5: Poor sleepers (http://uacc.arizona.edu/ sites/default/files/psqi_sleep_questionnaire_1_pg.pdf) (table 2).

\section{Form P}

Mortality, Severity (mild, moderate, severe), Complications (pancreatic, systemic).

\section{Statistical analysis}

\section{Variables}

All variables will be identified according to the outcomes mentioned in Endpoints section. They are categorical, continuous and scaled variables. See below:

Form A: Analysis of the continuous and categorical values.

Form B: Analysis of the continuous and categorical values.

Form C: The Diet*Calc Analysis Program can evaluate the questionnaire data (https://epi.grants.cancer.gov/ dhq2/dietcalc).

Form D: We will use the official scoring protocol to evaluate the survey (https://sites.google.com/site/theipaq/ scoring-protocol).

Form E: The original article contains the evaluation method $^{40}$

Form F: The scoring instruction is described in the original article. $^{44}$

Form P: Analysis of the continuous and categorical values. $^{34}$

Bias

Deriving from the study design, a possible recall bias could occur (patients who have the outcome (cases) are 
Table 2 Outputs, values, units and description of the Diet History Questionnaire II, the International Physical Activity Questionnaire, the Perceived Stress Scale and the Pittsburgh Sleep Quality Index

\begin{tabular}{|c|c|c|c|c|}
\hline Questionnaire & Outputs & Values & Unit & Description \\
\hline $\begin{array}{l}\text { Eating habits: } \\
\text { Diet History Questionnaire } \\
\text { II past year, with portion } \\
\text { size }\end{array}$ & $\begin{array}{l}176 \text { nutrients, dietary constituents and } \\
\text { food groups }\end{array}$ & Varied & $\begin{array}{l}\text { Varied: } \\
\mu \mathrm{gg} \\
\mathrm{mg} \\
\mathrm{g} \\
\mathrm{kcal} \\
\mathrm{IU}, \text { etc }\end{array}$ & $\begin{array}{l}\text { Food groups: } \\
\text { Carbohydrate } \\
\text { constituents } \\
\text { Macronutrients and } \\
\text { energy } \\
\text { Fats, fatty acids and } \\
\text { cholesterol } \\
\text { Protein constituents } \\
\text { Vitamins } \\
\text { Minerals } \\
\text { Carotenoids and } \\
\text { tocopherols } \\
\text { Dietary constituents } \\
\text { from supplements } \\
\text { Other } \\
\text { Food pyramid } \\
\text { equivalents }\end{array}$ \\
\hline \multirow{4}{*}{$\begin{array}{l}\text { Physical activity: } \\
\text { International Physical } \\
\text { Activity Questionnaire } \\
\text { long, last year version }\end{array}$} & Total walking activity & $0-$ & $\begin{array}{l}\text { MET-minutes/week } \\
\text { OR kcal/week }\end{array}$ & \\
\hline & Total moderate activity & $0-$ & $\begin{array}{l}\text { MET-minutes/week } \\
\text { OR kcal/week }\end{array}$ & \\
\hline & Total vigorous activity & $0-$ & $\begin{array}{l}\text { MET-minutes/week } \\
\text { OR kcal/week }\end{array}$ & \\
\hline & Total physical activity & $0-$ & $\begin{array}{l}\text { MET-minutes/week } \\
\text { OR kcal/week }\end{array}$ & \\
\hline \multirow{8}{*}{$\begin{array}{l}\text { Sleep: } \\
\text { Pittsburgh Sleep Quality } \\
\text { Index (PSQI) }\end{array}$} & Component 1: Subjective sleep quality & $0-3$ & Point & 0-good, 3-bad \\
\hline & Component 2: Sleep latency & $0-3$ & Point & 0-good, 3-bad \\
\hline & Component 3: Sleep duration & $0-3$ & Point & 0-good, 3-bad \\
\hline & $\begin{array}{l}\text { Component 4: Habitual sleep } \\
\text { efficiency }\end{array}$ & $0-3$ & Point & 0-good, 3-bad \\
\hline & Component 5: Sleep disturbances & $0-3$ & Point & 0-good, 3-bad \\
\hline & $\begin{array}{l}\text { Component } 6 \text { : Use of sleeping } \\
\text { medication }\end{array}$ & $0-3$ & Point & 0-good, 3-bad \\
\hline & Component 7: Daytime dysfunction & $0-3$ & Point & 0-good, 3-bad \\
\hline & Global PSQI score (general) & $0-21$ & Point & $\begin{array}{l}\text { Good sleep quality: } 0-5 \\
\text { Poor sleep quality: } 5-21\end{array}$ \\
\hline
\end{tabular}

MET, metabolic equivalent of task; NA, not applicable.

likely to remember the details of negative exposures more clearly than controls). It can be supposed that it appears randomly non-differential in the study groups.
Sample size

The sample size was originally calculated based on the end scores of the four questionnaires (HEI-2010, 
International Physical Activity Questionnaire (IPAQ), PSS, PSQI). All calculations were made using a $5 \%$ significance level, a power of $80 \%$, a $40 \%$ difference between the group means and equal sample size ratio (age, sex and socioeconomic-matched control groups). We used an online sample size calculator (http://clincalc.com/ Stats/SampleSize.aspx).

We achieved the required information, for example, mean and SD from articles (references found after each calculated sample size) or from online databases (HEI scores). In the case of two questionnaires (PSQI and PSS), we made the calculation based also on Hungarian and non-Hungarian data sources. The required sample sizes for the questionnaires per group are the following:

- HEI-2010 Score: 195 (National Health and Nutrition Examination Survey, 2011-2012, results in https:// www.cnpp.usda.gov/healthyeatingindex);

- IPAQ Total activity: $155^{45}$;

- PSS Score: 217 and $13,{ }^{46} 23^{47}$;

- PSQI Score: $231^{48} 187 .^{49}$

\section{Statistical methods}

All the collected variables will be characterised using descriptive statistical method. Depending on the distribution, data will be represented as mean and SD or median with IQRs; categorical variables will be given in quantity and percentages.

In order to observe the differences, the endscores and subscale scores of the questionnaires, other parameters such as race, BMI, waist circumference, education, occupation, income and subjective social status will be univariately compared between the AP and the control groups. In case of binary outcomes, $\chi^{2}$ test in case of continuous variables, ANOVA or Kruskal-Wallis test with Bonferroni correction will be used provided by the distribution of the data.

Multivariable analysis will be applied to identify lifestyle factors that influence the risk of developing AP. To detect these factors, conditional logistic regression and multivariate mixed-effects linear regression will be performed where the matched pairs will be handled as random subjects.

The case groups and control groups will be matched by the next three criteria: age, gender and location. During the match, two controls will belong to each patient (case); the match tolerance will be set for age: \pm 5 years, gender: exact, location of residence: situated in the same country and $\pm 15 \%$ of the population.

In order to identify possible patients' outcomes (eg, severity of AP or mortality), the end scores of the questionnaires (DHQII, IPAQ, PSS, PSQI) and the variables from Forms A and B will be used in hierarchical cluster analysis using Ward's method and the squared Euclidean distance.

For the effect of the parameters on survival, KaplanMeier survival analysis followed by multivariable Cox proportional-hazards model will be used among classes. We will calculate $\mathrm{HR}$, relative risk $(\mathrm{RR})$ and $\mathrm{RR}$ reductions with corresponding $95 \%$ CIs. All statistical analysis will be handled with a significance level of $5 \%$.

\section{DISCUSSION}

This is the first study in which the relevant patientreported retrospective data will be collected in a prospective manner, and the associations between socioeconomic factors, dietary habits, physical activity, chronic stress, sleep quality and AP will be investigated. We hope to find both negative and positive associations which will allow for the first time to suggest lifestyle modifications for patients discharged from the hospitals after AP or for those who wish to reduce their risk for AP.

\section{Centres}

The study will start with the following centres: University of Szeged, University of Pécs, University of Debrecen and Szent György University Teaching Hospital of Fejér County; however, other centres are welcome to participate in the LIFESPAN as an open-label study. Completion of the LETTER OF INTENT form will be mandatory for registering the participation of each institution. HPSG will acknowledge receipt of the LETTER OF INTENT form and will contact centres providing them with additional study information. Each centre must provide the same number of individuals for all the relevant four groups (one case and three controls).

\section{Publication policy}

Centres providing more than 40 individuals can provide an author to the authors' list. Every additional 20 individuals will give the opportunity to nominate an author.

\section{Dissemination policy}

We plan to communicate the results to several members of the healthcare system including medical doctors, dietitians, nurses, patients and so on. We plan to publish the results in a peer-reviewed high-quality journal for professionals. In addition, we also plan to publish it for lay readers in order to maximise the dissemination and benefits of this study.

\section{Feasibility and earlier experience}

The feasibility will be examined by a pilot enrolment of 20 individuals in each group.

\section{Safety}

This is a non-interventional observational clinical study. Since no unknown drugs/therapy are used in the study, no adverse and serious adverse events are expected/interpretable during the study.

Since no additional treatment is necessary for the study, the general healthcare costs are covered by the National Healthcare System (University of Pécs Medical School). This study was designed with the help of the Centre for Translational Medicine at the University of Pécs. This centre is committed to improve patients' lives with research activities like registries, and observational and 
interventional study organisations (https://tm-centre. org). For joining centres, the additional local costs have to be covered by the centre.

\section{Trial status}

Protocol version: V1.0 08.01.2019.

Start of patient recruitment: April 2019.

Planned finish of the study: 30 November 2023.

\section{Author affiliations}

${ }^{1}$ First Department of Medicine, University of Szeged, Szeged, Hungary

${ }^{2}$ Institute for Translational Medicine, Medical School, University of Pécs, Pécs, Hungary

${ }^{3}$ Department of Public Health Medicine, Medical School, University of Pécs, Pécs, Hungary

${ }^{4}$ Institute of Bioanalysis, Medical School, University of Pécs, Pécs, Hungary

${ }^{5}$ Division of Gastroenterology, Department of Internal Medicine, Faculty of Medicine, University of Debrecen, Debrecen, Hungary

${ }^{6}$ Division of Gastroenterology, First Department of Medicine, Medical School, University of Pécs, Pécs, Hungary

${ }^{7}$ Szent György University Teaching Hospital of Fejér County, Székesfehérvár, Hungary

${ }^{8}$ County Emergency Clinical Hospital - Gastroenterology, George Emil Palade University of Medicine, Pharmacy, Science and Technology of Targu Mures, Targu Mures, Romania

${ }^{9}$ George Emil Palade University of Medicine, Pharmacy, Science and Technology of Targu Mures, Targu Mures, Romania

${ }^{10}$ Department of Medicine A, Universitatsmedizin Greifswald, Greifswald, Germany

${ }^{11}$ Department of General Surgery, University of Heidelberg, Heidelberg, Germany

${ }^{12}$ Department of Surgery, University of California, Los Angeles, United States

${ }^{13}$ School of Biosciences, Cardiff University, Cardiff, UK

${ }^{14}$ MTA-SZTE Translational Gastroenterology Research Group, University of Szeged, Szeged, Hungary

${ }^{15}$ Division of Translational Medicine, First Department of Medicine, Medical School, University of Pécs, Pécs, Hungary

Correction notice This article has been corrected since it was published. Author name Miklós Sahin-Tóth has been updated.

Acknowledgements We would like to thank all the interviewed individuals for providing useful information on personal experience concerning acute pancreatitis, inquiring about lifestyle elements, hereby contributing to designing the study and constructing the questionnaires.

Contributors BK, ED, ZG, JG, NF, MP, FI, AV and PH designed the study. As a member of the ITAB, MML, JN, MS-T and OHP gave advices and will continuously monitor the progress of the study. ZV, KM, PH, BE, DP, EF, TJ, LG, DE, VD-V, SK and IT drafted the manuscript, and AS, JA and NZ edited the text. AS, JA and NZ adapted the tables. All authors read and approved the final manuscript.

Funding Centre costs (IT, biostatistics, study organisation, etc) are covered by the University of Pécs Medical School, Momentum Grant of the Hungarian Academy of Sciences (LP2014-10/2014); and Economic Development and Innovation Operative Programme Grant and Highly Cited Publication Grant of the National Research, Development and Innovation Office (GINOP-2.3.2-15-2016-00048 Stay Alive, KH-125678 and EFOP 3.6.2-16- 2017-00006 Live Longer), and Translational Medicine Foundation. The study was designed by the SC and ITAB. DMC and SP have not been involved in the design of the study; moreover, the SP will have no access to database.

Competing interests None declared.

Patient consent for publication Not required.

Ethics approval The study has been registered at the ISRCTN (25940508) and received the relevant ethical approval from the Scientific and Research Ethics Committee of the Hungarian Medical Research Council under reference number 54175-2/2018/EKU.

Provenance and peer review Not commissioned; externally peer reviewed.

Open access This is an open access article distributed in accordance with the Creative Commons Attribution Non Commercial (CC BY-NC 4.0) license, which permits others to distribute, remix, adapt, build upon this work non-commercially, and license their derivative works on different terms, provided the original work is properly cited, appropriate credit is given, any changes made indicated, and the use is non-commercial. See: http://creativecommons.org/licenses/by-nc/4.0/.

ORCID iD

Péter Hegyi http://orcid.org/0000-0002-7035-941X

\section{REFERENCES}

1 Salmerón J, Ascherio A, Rimm EB, et al. Dietary fiber, glycemic load, and risk of NIDDM in men. Diabetes Care 1997;20:545-50.

2 Salmerón J, Manson JE, Stampfer MJ, et al. Dietary fiber, glycemic load, and risk of non-insulin-dependent diabetes mellitus in women. JAMA 1997;277:472-7.

3 Hu FB, Stampfer MJ, Manson JE, et al. Dietary fat intake and the risk of coronary heart disease in women. N Engl J Med 1997;337:1491-9.

4 Riboli E, Hunt KJ, Slimani N, et al. European prospective investigation into cancer and nutrition (EPIC): study populations and data collection. Public Health Nutr 2002;5:1113-24.

5 Setiawan VW, Pandol SJ, Porcel J, et al. Dietary factors reduce risk of acute pancreatitis in a large multiethnic cohort. Clin Gastroenterol Hepatol 2017:15:257-65.

6 Kolonel LN, Henderson BE, Hankin JH, et al. A multiethnic cohort in Hawaii and Los Angeles: baseline characteristics. Am J Epidemiol 2000;151:346-57.

7 Oskarsson V, Sadr-Azodi O, Orsini N, et al. Vegetables, fruit and risk of non-gallstone-related acute pancreatitis: a population-based prospective cohort study. Gut 2013;62:1187-92.

8 Oskarsson V, Orsini N, Sadr-Azodi O, et al. Fish consumption and risk of non-gallstone-related acute pancreatitis: a prospective cohort study. Am J Clin Nutr 2015;101:72-8.

9 Haskell WL, Lee I-M, Pate RR, et al. Physical activity and public health: updated recommendation for adults from the American College of sports medicine and the American heart association. Med Sci Sports Exerc 2007;39:1423-34.

10 Pate RR, Pratt M, Blair SN, et al. Physical activity and public health. A recommendation from the centers for disease control and prevention and the American College of sports medicine. JAMA 1995;273:402-7.

11 Petersen AMW, Pedersen BK. The anti-inflammatory effect of exercise. J Appl Physiol 2005;98:1154-62.

12 Byrne KR, Adler DG. Marathon pancreatitis: a distinct clinical entity. J Clin Gastroenterol 2011;45:178-9.

13 Pang Y, Kartsonaki C, Turnbull I, et al. Metabolic and lifestyle risk factors for acute pancreatitis in Chinese adults: a prospective cohort study of 0.5 million people. PLoS Med 2018;15:e1002618.

14 Adler NE, Boyce WT, Chesney MA, et al. Socioeconomic inequalities in health. No easy solution. JAMA 1993;269:3140-5.

15 Ellis MP, French JJ, Charnley RM. Acute pancreatitis and the influence of socioeconomic deprivation. Br J Surg 2009;96:74-80.

16 Yudkin JS, Kumari M, Humphries SE, et al. Inflammation, obesity, stress and coronary heart disease: is interleukin-6 the link? Atherosclerosis 2000;148:209-14.

17 Meier-Ewert HK, Ridker PM, Rifai N, et al. Effect of sleep loss on Creactive protein, an inflammatory marker of cardiovascular risk. J Am Coll Cardiol 2004;43:678-83.

18 Shamsuzzaman ASM, Winnicki M, Lanfranchi P, et al. Elevated Creactive protein in patients with obstructive sleep apnea. Circulation 2002;105:2462-4.

19 Clyne B, Olshaker JS. The C-reactive protein. J Emerg Med 1999;17:1019-25.

20 Chan A-W, Tetzlaff JM, Altman DG, et al. SPIRIT 2013 statement: defining standard protocol items for clinical trials. Ann Intern Med 2013;158:200-7.

21 Hritz I, Hegyi P. Early achievable severity (easy) index for simple and accurate expedite risk stratification in acute pancreatitis. $J$ Gastrointestin Liver Dis 2015;24.

22 Párniczky A, Mosztbacher D, Zsoldos F, et al. Analysis of pediatric pancreatitis (APPLE trial): pre-study protocol of a multinational prospective clinical trial. Digestion 2016;93:105-10.

23 Zsoldos F, Párniczky A, Mosztbacher D, et al. Pain in the early phase of pediatric pancreatitis (PINEAPPLE Trial): pre-study protocol of a multinational prospective clinical trial. Digestion 2016;93:121-6.

24 Dubravcsik Z, Madácsy L, Gyökeres T, et al. Preventive pancreatic stents in the management of acute biliary pancreatitis (PREPAST trial): Pre-study protocol for a multicenter, prospective, randomized, interventional, controlled trial. Pancreatology 2015;15:115-23. 
25 Márta K, Szabó AN, Pécsi D, et al. High versus low energy administration in the early phase of acute pancreatitis (GOULASH trial): protocol of a multicentre randomised double-blind clinical trial. BMJ Open 2017;7:e015874.

26 Dubravcsik Z, Farkas G, Hegyi P, et al. Autoimmune pancreatitis. Evidence based management guidelines of the Hungarian Pancreatic Study Group. Orv Hetil 2015;156:292-307.

27 Hritz I, Czakó L, Dubravcsik Z, et al. Acute pancreatitis. Evidence based management guidelines of the Hungarian Pancreatic Study Group. Orv Hetil 2015;156:244-61.

28 Párniczky A, Czakó L, Dubravcsik Z, et al. Pediatric pancreatitis. Evidence based management guidelines of the Hungarian Pancreatic Study Group. Orv Hetil 2015;156:308-25.

29 Takács T, Czakó L, Dubravcsik Z, et al. Chronic pancreatitis. Evidence based management guidelines of the Hungarian Pancreatic Study Group. Orv Hetil 2015;156:262-88.

30 Fischer $\mathrm{H}$. A history of the central limit theorem: from classical to modern probability theory. New York: Springer, 2011.

31 Whitcomb DC. Genetics and alcohol: a lethal combination in pancreatic disease? Alcohol Clin Exp Res 2011;35:838-42.

32 Adiamah A, Psaltis E, Crook M, et al. A systematic review of the epidemiology, pathophysiology and current management of hyperlipidaemic pancreatitis. Clinical Nutrition 2018;37:1810-22.

33 Giatti L, Camelo LdoV, Rodrigues JFdeC, et al. Reliability of the MacArthur scale of subjective social status - Brazilian Longitudina Study of Adult Health (ELSA-Brasil). BMC Public Health 2012;12.

34 Párniczky A, Kui B, Szentesi A, et al. Prospective, multicentre nationwide clinical data from 600 cases of acute pancreatitis. PLoS One 2016;11:19.

35 Subar AF. Developing dietary assessment tools. J Am Diet Assoc 2004:104:769-70.

36 Thompson FE, SUBAR AMYF, BROWN CC, et al. Cognitive research enhances accuracy of food frequency questionnaire reports: results of an experimental validation study. J Am Diet Assoc 2002;102:212-25.

37 Subar AF, Thompson FE, Kipnis V, et al. Comparative validation of the block, Willett, and National cancer Institute food frequency questionnaires. Am J Epidemiol 2001;154:1089-99.
38 Kipnis Vet al. Structure of dietary measurement error: results of the OPEN biomarker study. Am J Epidemiol 2003;158:14-21.

39 Craig CL, Marshall AL, Sjöström M, et al. International physical activity questionnaire: 12 -country reliability and validity. $\mathrm{Med} \mathrm{Sci}$ Sports Exerc 2003;35:1381-95.

40 Cohen S, Kamarck T, Mermelstein R. A global measure of perceived stress. J Health Soc Behav 1983;24:385-96.

41 Cobb JMT, Steptoe A. Psychosocial stress and susceptibility to upper respiratory tract illness in an adult population sample. Psychosom Med 1996;58:404-12.

42 Glaser R, Kiecolt-Glaser JK, Marucha PT, et al. Stress-related changes in proinflammatory cytokine production in wounds. Arch Gen Psychiatry 1999;56:450-6.

43 Stowell JR, Kiecolt-Glaser JK, Glaser R. Perceived stress and cellular immunity: when coping counts. J Behav Med 2001;24:323-39.

44 Buysse DJ, Reynolds CF, Monk TH, et al. The Pittsburgh sleep quality index: a new instrument for psychiatric practice and research. Psychiatry Res 1989;28:193-213.

45 Bourdeaudhuij ID, Teixeira PJ, Cardon G, et al. Environmental and psychosocial correlates of physical activity in Portuguese and Belgian adults. Public Health Nutr 2005;8:886-95.

46 Stauder A, Konkolÿ Thege B. Az észlelt stressz kérdöív (PSS) magyar verziójának jellemzői. Mentálhigiéné és Pszichoszomatika 2006;7:203-16

47 Cohen S, Williamson G. Perceived stress in a probability sample of the US. In: Spacapam S, Oskamp S, eds. The social psychology of health: Claremont symposium on applied social psychology. Newbury Park, CA: Sage, 1988: 31-67.

48 Takács J, Bódizs R, Ujma PP, et al. Reliability and validity of the Hungarian version of the Pittsburgh sleep quality index (PSQI-HUN): comparing psychiatric patients with control subjects. Sleep Breath 2016;20:1045-51.

49 Buysse DJet al. Relationships between the Pittsburgh sleep quality index (PSQI), Epworth Sleepiness scale (ESS), and clinical/ polysomnographic measures in a community sample. J Clin Sleep Med 2008;4:563-71. 